\title{
Modeling of Hydrogen Adsorption Phenomenon in Amorphous Silica Using Molecular Dynamics Method
}

\author{
J. F. Fatriansyah ${ }^{1}$, D. Dhaneswara ${ }^{1}$, M. H. Abdurrahman ${ }^{1}$, F. R. Kuskendrianto ${ }^{1}$, M. B. Yusuf ${ }^{1}$ \\ ${ }^{1}$ Metallurgy and Materials Engineering Department, Faculty of Engineering, University of Indonesia, \\ Kampus Baru UI Depok, Depok, 16424, Jawa Barat, Indonesia.
}

Received 9 October 2019; Accepted 16 November 2019

Available online 28 February 2020

\begin{abstract}
Hydrogen is one of the future source energy because it has environmentally friendly. However, there are still some problems in the storage method of hydrogen. In several studies, it was found that silicon-based material is a promising candidate as a hydrogen storage medium. In this study, the effect of various temperature and pressure to the adsorption of hydrogen on amorphous silica with molecular dynamics simulation using Lennard-Jones potential. In this simulation, the temperature that i used are 233, 253, 273 and $293 \mathrm{~K}$ with pressure at each temperature are $1,2,5,10$, and $15 \mathrm{~atm}$. The simulations had successfully visualized and indicate that amorphous silica has a good hydrogen storage capability where temperature and pressure affect the amount of hydrogen adsorbed. At low temperature $(233 \mathrm{~K})$, the hydrogen concentrations are relatively high than at higher temperature. The best result of hydrogen capacity is $0.048116 \%$ that occurred at high pressure (15 atm) with low temperature $(233 \mathrm{~K})$ condition.
\end{abstract}

Keywords: hydrogen storage, amorphous silica, molecular dynamics simulation, Lennard-Jones potential, adsorption

\section{Introduction}

Human daily life can not be separated from energy. Energy has an enormous a role in every human activity, especially in an era when population is growing and technology become important. The need for energy will also increase with this condition. This must be accompanied by an enhancement in the amount of energy. Nowadays, there is a lot of research for finding the best renewable energy to be able to meet energy needs in the future. Hydrogen is one of the renewable energy source that attracts a lot of attention because it is environmentally friendly (Dutta, 2014). The reaction from hydrogen does not produce $\mathrm{CO}_{2}$ (Marbán \& Valdés-solís, 2007). Hydrogen has a higher heating value than petroleum beside it known as the cleanest fuel (Zhou, 2005). It also began to use in various applications with the advantages possessed by hydrogen. Although hydrogen has many advantages, there are still some obstacles in developing it, including the safety and storage problem (Durbin \& Malardier-Jugroot, 2013).

Hydrogen can be store by many ways include compression, liquefaction, metallic hydrides and adsorption on material (Durbin \& Malardier-Jugroot, 2013; F. Zhang, Zhao, Niu, \& Maddy, 2016; Zhou, 2005; Züttel, 2003). At the moment, adsorption is chosen for reasons of cost which is cheaper, and more safety than another method. This method has a fast kinetics and the binding energy of hydrogen is low (F. Zhang et al., 2016). In addition, adsorption can work under conditions of low pressure and the design of the storage system is quite simple. The type of adsorption that use here is physisorption (physical adsorption) which occurs when a molecule is adsorbed on solid surface due to the van der Waals interaction. The van der Waals force occurs when the attractive force that occurs

\footnotetext{
* Corresponding author

E-mail address: mhdhanif86@yahoo.com
} 
between the adsorbate and the surface of the adsorbent is relatively weak (Abe, Popoola, Ajenifuja, \& Popoola, 2019). In this study $\mathrm{H}_{2}$ chemisorption will not happen since the binding energy is low. But for materials such as metal, the chemisorption is possible which may exists in the form or corrosion. It is necessary to pay attention in the type of material that used as a storage medium because it must have a large surface area. Some examples of materials used as storage media are carbon-based materials like graphene, graphite, carbon nanotubes (CNT), and metal organic frameworks (MOF) (Dalebrook, Gan, \& Grasemann, 2013; Hudson et al., 2009; Zubizarreta, Arenillas, \& Pis, 2009). Silicon surfaces, silica and zeolites are some of silicon-based materials that are also began to be seen for hydrogen storage applications (Du, Huang, \& Wu, 2011; Dürr \& Höfer, 2006; Fatriansyah, Dhaneswara, Abdurrahman, Kuskendrianto, \& Yusuf, 2019). For example, MWNT (Multi-walled carbon nanotubes) at $300 \mathrm{~K}$ has a hydrogen capacity around $3.7 \mathrm{wt} \%$ and zeolites around $1.6 \mathrm{wt} \%$ at $298 \mathrm{~K}$ (Gundiah, Govindaraj, Rajalakshmi, Dhathathreyan, \& Rao, 2003; Li \& Yang, 2006).

Silica is an abundant material that has many advantages including inexpensive, good thermal stability, inert and harmless (Dhaneswara, Utami, Adriyani, Putranto, \& Delayori, 2018). With these kinds of attributes, it can solve several problems such as cost, safety and storage capacity. Therefore, amorphous silica can be one of the promising candidates as hydrogen storage media. The way to study this research by using molecular dynamics simulation because it can reduce the cost of experiment and molecular dynamics are used to observe the structure of substances such as solid, liquid, and gas. The force on each molecule will also be calculated. In previous studies, we have simulated hydrogen adsorption in amorphous silica with variations in pressure at $273 \mathrm{~K}$ (Fatriansyah et al., 2019). However, there are still many factors that can influence the capacity of hydrogen storage within this material. In this study, we want to investigate the effect of temperature and behavior on hydrogen adsorption in amorphous silica with molecular dynamics method which is cost-effective.

\section{Materials and Methods}

The software that we use for running this simulation is LAMMPS (Large-scale Atomic/Molecular Massively Parallel Simulator). At the beginning, all molecules of hydrogen and silica was build in the VMD (Visual Molecular Dynamics). The hydrogen is located near the surface of the amorphous silica. While silica formed with inorganic builder features on VMD is arranged so that it make shaped like a cube wall. Each of molecules are given different colors making it easier to identify the type of compound. The simulation is based on Lennard-Jones equation to defined interaction between atoms. Equation 1 is the lennard jones equation. The Lennard-Jones parameters that we used in this simulation is displayed in Table 1.

$$
U=4 \varepsilon\left\{\left(\frac{\sigma}{r}\right)^{12}-\left(\frac{\sigma}{r}\right)^{6}\right\}
$$

$\sigma$ is the interaction length parameter and $\varepsilon$ is the interaction strength parameters.

Table 1. Lennard-Jones Interaction Parameter (Mashayak \& Aluru, 2012).

\begin{tabular}{ccc}
\hline Atom & $\sigma(\AA)$ & $\varepsilon(\mathrm{kJ} / \mathrm{mol})$ \\
\hline $\mathrm{H}$ & 0 & 0 \\
$\mathrm{Si}$ & 3.385 & 2.4522 \\
$\mathrm{O}$ & 3.17 & 0.6503 \\
\hline
\end{tabular}

The parameters in Table 1 are also used to determine the pair coefficient of each atom. Where each particle is labeled $\mathrm{i}$ and $\mathrm{j}$ and in its calculation the Lorentz-Berthelot equation is used as shown in equations 2 and 3 .

$$
\varepsilon_{i j}=\sqrt{\varepsilon_{i j} \varepsilon_{j j}}
$$




$$
\sigma_{i j}=\frac{\sigma_{i j}+\sigma_{j j}}{2}
$$

The operating conditions in this study will be influenced by temperature and pressure. Hydrogen adsorption is carried out at temperatures of 233, 253, 273 and $293 \mathrm{~K}$ at various pressure (1, 2, 5, 10, and $15 \mathrm{~atm})$. The previous study just do simulation in one temperature (Fatriansyah et al., 2019). Therefore, in this simulation it can be seen the effect of temperature on the adsorption process and also see the effect of pressure at each temperature. The variable temperature that we choose is to know the effect of temperature in room temperature condition and above and also below the room temperature. In addition to the Lennard Jones equation, we also use the modification of ideal gas equation to calculate the pressure needed at each temperature so that the pressure can be fixed at each simulation run. The equation is shown in equation 4.

$$
\left\{P+a\left(\frac{n}{V_{m}}\right)^{2}\right\}\left(V_{m}-n b\right)=n R T
$$

$P$ is pressure, $a$ and $b$ represent the coefficient of van der Waals for hydrogen, while $V_{m}$ is volume of the system, $R$ is the gas constant and $T$ for temperature. The volume of this simulation is $3,43 \times 10^{-25}$ $m^{3}$.

The results of the simulation can be visualized so that the behavior of hydrogen adsorption can be seen and the amount of hydrogen that can be adsorbed in silica can be known. Equation 5 show the calculation to get the capacity of hydrogen that can be stored in silica.

$$
\rho_{w}=\frac{N_{\mathrm{H}} m_{\mathrm{H}}}{N_{\mathrm{Si}} m_{\mathrm{Si}}+N_{\mathrm{O}} m_{\mathrm{O}}+N_{\mathrm{H}} m_{\mathrm{H}}} .
$$

$\mathrm{N}$ and $\mathrm{m}$ are the number of atoms or molecules and atomic relative masses, respectively.

\section{Results and Discussion}

Table 2. Initial hydrogen molecules amount in various pressure and temperature.

\begin{tabular}{ccccc}
\hline & \multicolumn{4}{c}{ Amount of Molecules } \\
\cline { 2 - 5 } Pressure (atm) & $233 \mathrm{~K}$ & $253 \mathrm{~K}$ & $273 \mathrm{~K}$ & $293 \mathrm{~K}$ \\
\hline 1 & 11 & 10 & 9 & 9 \\
2 & 22 & 20 & 18 & 17 \\
5 & 54 & 50 & 46 & 43 \\
10 & 108 & 100 & 92 & 86 \\
15 & 162 & 149 & 138 & 129 \\
\hline
\end{tabular}

This simulation was carried out under conditions of temperature 233, 253, 273 and $293 \mathrm{~K}$ with varying pressures $(1,2,5,10$, and $15 \mathrm{~atm})$ fixed at each temperature. Equation 4 is used to determine the amount of hydrogen at initial conditions to make a constant pressure at each temperature. the number of initial conditions of each temperature and pressure can be seen in Table 2 in this simulation the absorbed hydrogen is calculated at every 10000 time step with the number of running times in each simulation of 500000 .

In Figure 1 can be seen the mechanism of hydrogen adsorption at a temperature of $233 \mathrm{~K}$ with different pressure variations. Hydrogen is indicated by a red atom. Silica molecules are shown by blue and white atoms. Blue atoms are silicon and white atoms are oxygen. In Figure 1 it can be seen that with increasing pressure, the amount of hydrogen absorbed on the surface of amorphous silica will also increase. This can also be seen in Figures 2, 3 and 4. 


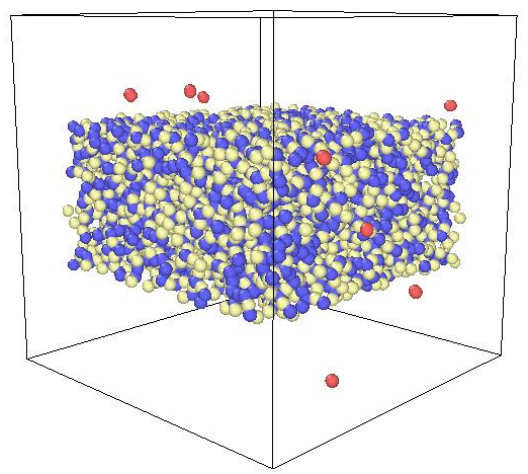

(a)

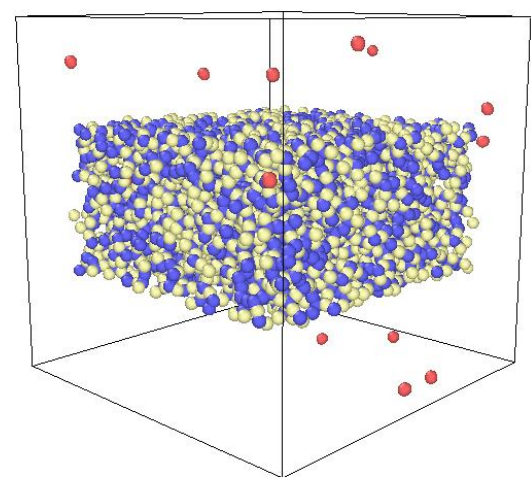

(b)

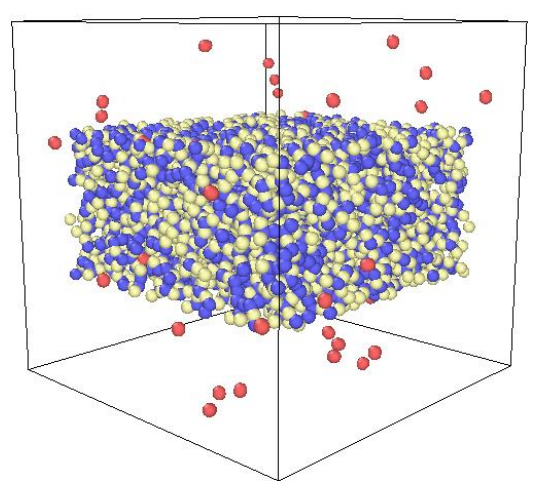

(c)

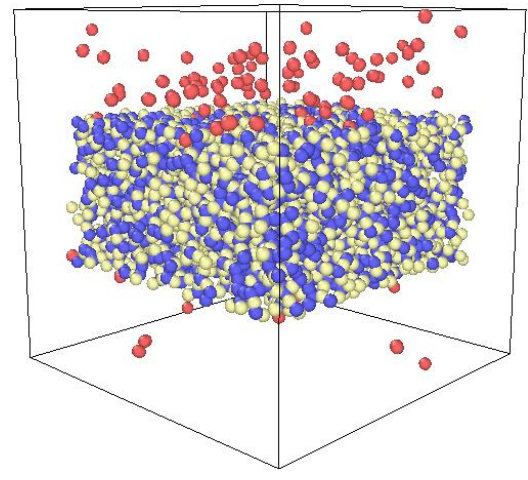

(d)

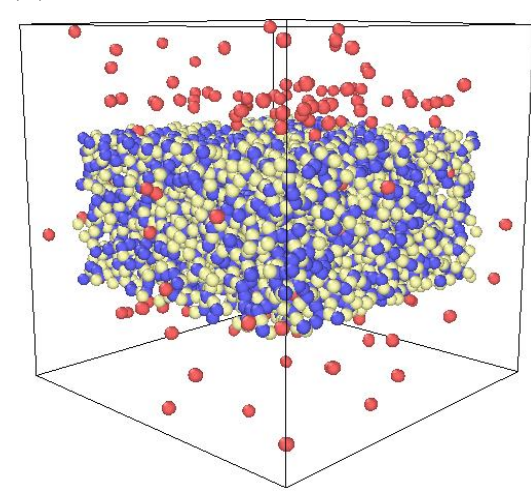

(e)

Figure 1. Final condition of hydrogen adsorption in $233 \mathrm{~K}$ at (a) $1 \mathrm{~atm}$, (b) $2 \mathrm{~atm}$, (c) $5 \mathrm{~atm}$, (d) 10 atm, and (e) $15 \mathrm{~atm}$.

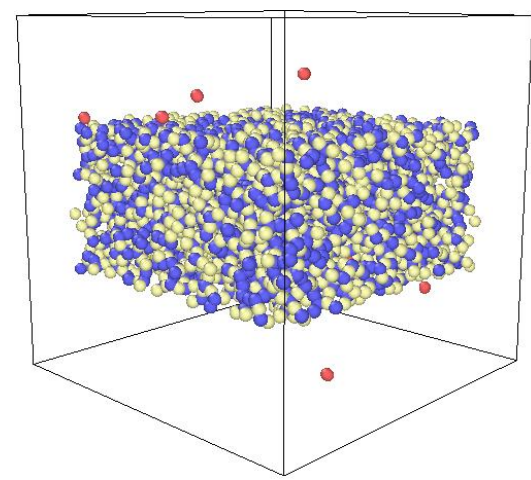

(a)

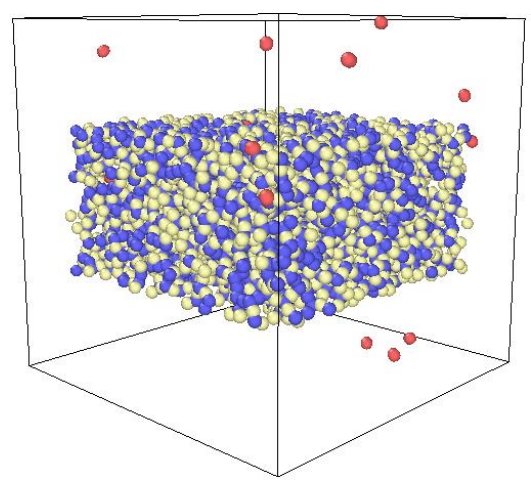

(b)

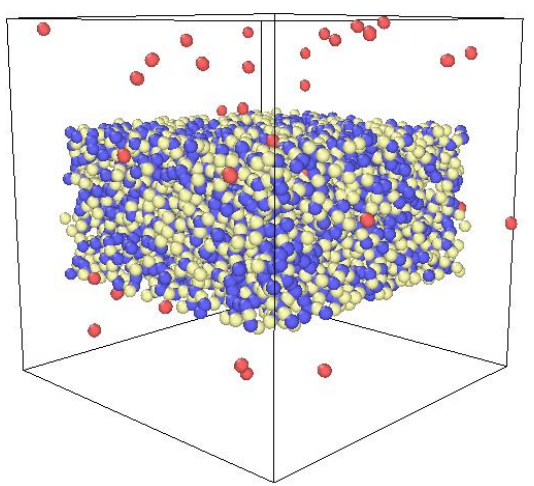

(c)

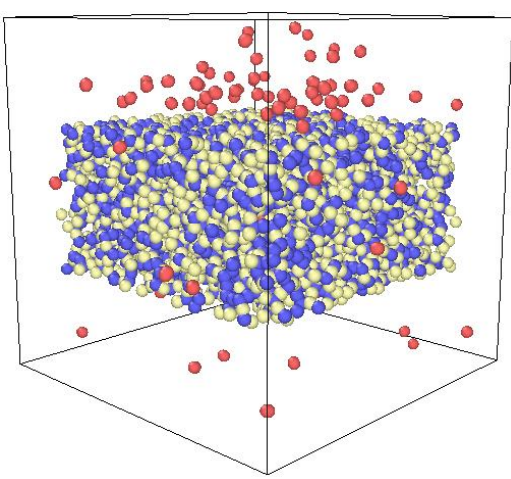

(d)

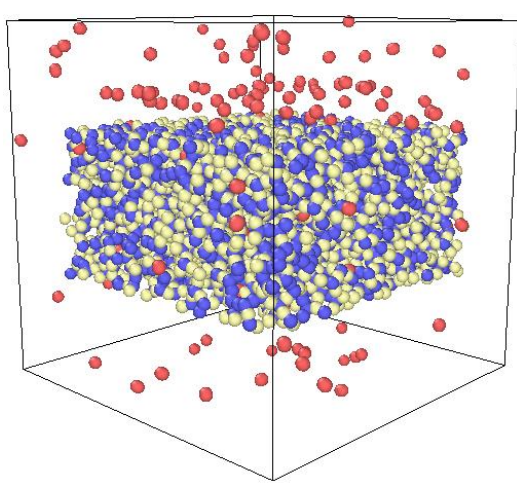

(e)

Figure 2. Final condition of hydrogen adsorption in $253 \mathrm{~K}$ at (a) $1 \mathrm{~atm}$, (b) $2 \mathrm{~atm}$, (c) $5 \mathrm{~atm}$, (d) 10 atm, and (e) $15 \mathrm{~atm}$. 


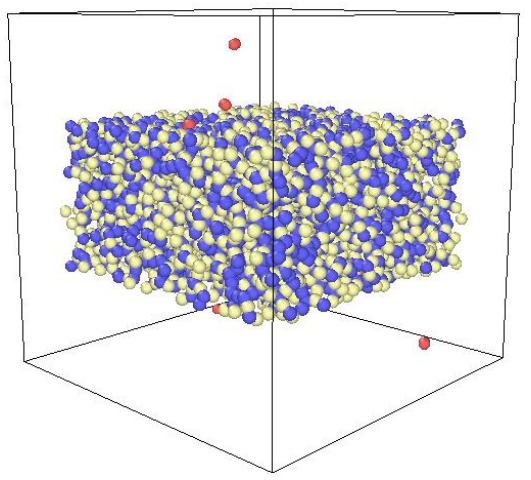

(a)

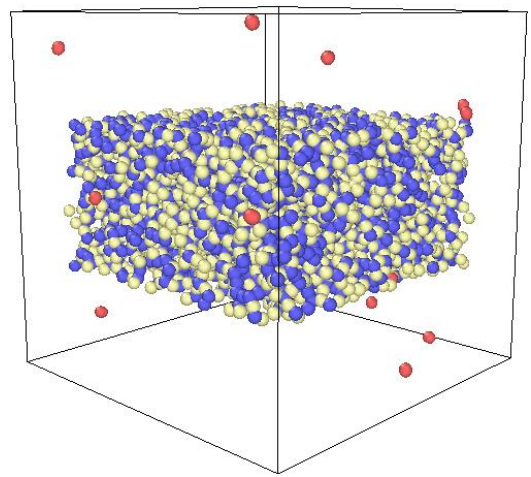

(b)

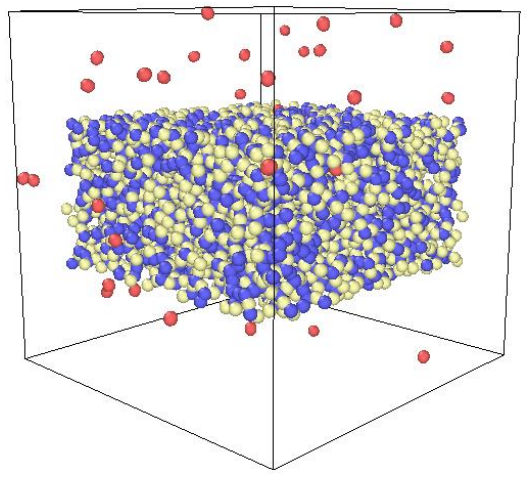

(c)

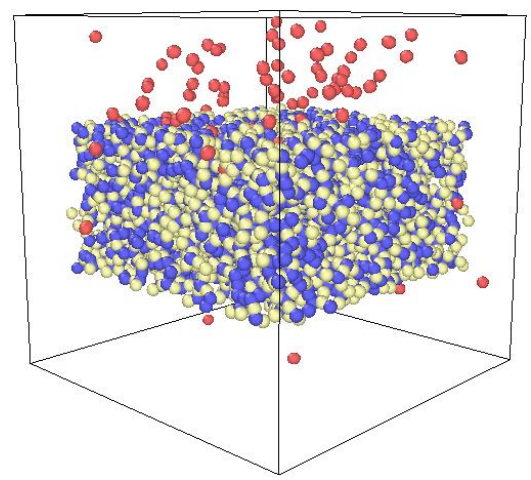

(d)

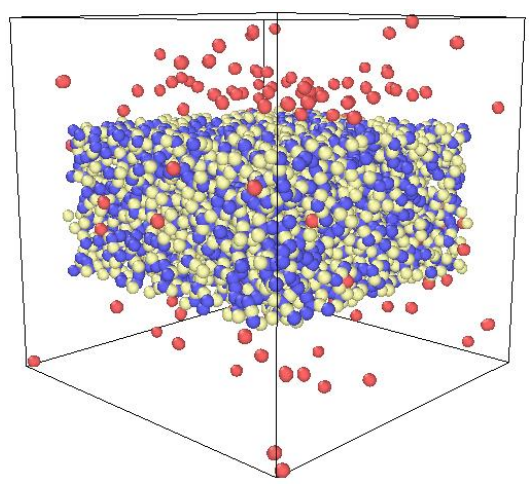

(e)

Figure 3. Final condition of hydrogen adsorption in $273 \mathrm{~K}$ at (a) $1 \mathrm{~atm}$, (b) $2 \mathrm{~atm}$, (c) $5 \mathrm{~atm}$, (d) 10 atm, and (e) $15 \mathrm{~atm}$.

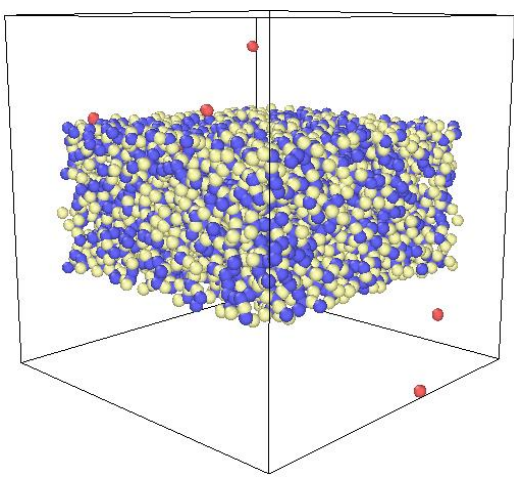

(a)

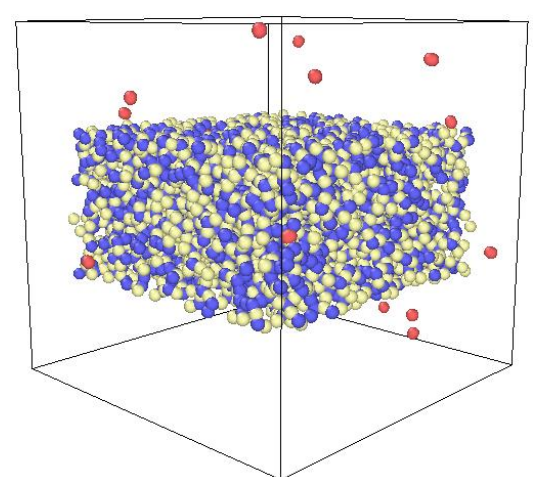

(b)

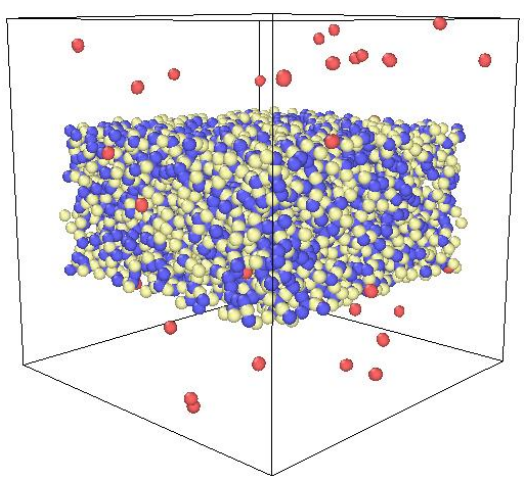

(c)

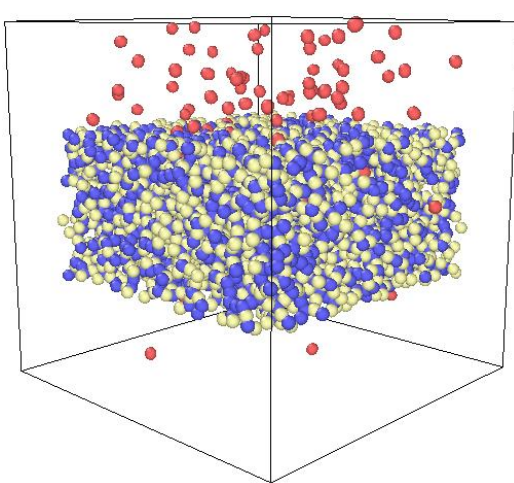

(d)

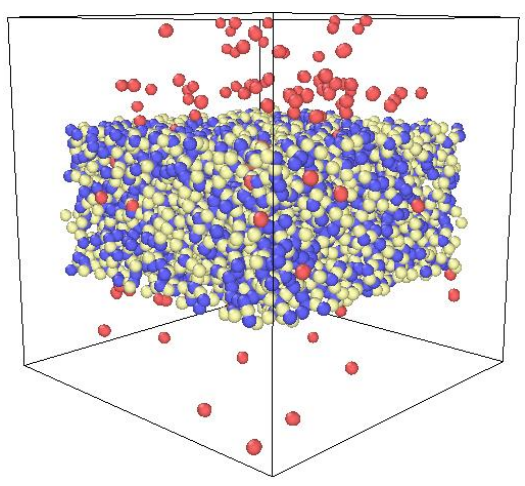

(e)

Figure 4. Final condition of hydrogen adsorption in $293 \mathrm{~K}$ at (a) $1 \mathrm{~atm}$, (b) $2 \mathrm{~atm}$, (c) $5 \mathrm{~atm}$, (d) 10 atm, and (e) $15 \mathrm{~atm}$. 
In Figure 5 (a), we can see the graph between the concentration of hydrogen to the number of timesteps in $233 \mathrm{~K}$ at varying pressures. It can be seen that hydrogen adsorption is influenced by pressure and time. With increasing pressure, the amount of hydrogen absorbed also increases. In addition, in Figure 5 (a) it can be seen that with increasing running time, the amount of hydrogen concentration will also increase. At certain times the hydrogen adsorption on the silica will be stable especially in the 480000 timestep. Hydrogen adsorption is saturated at that point because a material has the maximum capacity to absorb fluid or gas depending on the interaction between the two components.

Figure 5 (b) shows the optimum point of hydrogen adsorption at saturation at $233 \mathrm{~K}$, starting from 480000 running time. At this temperature the lowest amount of hydrogen concentration is at a pressure of $1 \mathrm{~atm}$ with a value of $0.004667 \% \mathrm{wt}$. While the highest amount of hydrogen concentration is at a pressure of $15 \mathrm{~atm}$ with a value of $0.048116 \% \mathrm{wt}$. In this case the concentration of absorbed hydrogen will increase with increasing pressure.

In Figure 6 we can see a graph of the hydrogen concentration to the number of timestep at pressure 1 atm, $2 \mathrm{~atm}, 5 \mathrm{~atm}, 10 \mathrm{~atm}$, and $15 \mathrm{~atm}$. Pressure and time affect the process of hydrogen adsorption seen in Figure 6 (a). The more amount of adsorbed hydrogen, with increasing pressure. There is an effect of time on hydrogen adsorption, by increasing the running time, then the amount of concentration of absorbed hydrogen will also increase.

The trend that occurs at temperatures $233 \mathrm{~K}$ and $253 \mathrm{~K}$ also occurs at temperatures $273 \mathrm{~K}$ and $293 \mathrm{~K}$ as shown in Figures 7 and 8. Where from a pressure of 1 to $15 \mathrm{~atm}$ there is an increase in the amount of hydrogen concentration. This is in accordance with $\mathrm{Wu}$ et al .'s research, where the adsorption process is more likely to be carried out at high pressure to get more results (Wu, Fang, \& Lo, 2012).

Furthermore, Figure 6 (b) shows the optimum point of hydrogen adsorption at its saturation state at 253 $\mathrm{K}$, starting from 480000 . However, at some other pressure saturation has started before 480000 running time. This shows the pressure and running time at that moment of the material is no longer able to absorb hydrogen so saturation occurs. At this temperature the lowest amount of hydrogen concentration is at a pressure of $1 \mathrm{~atm}$ with a value of $0.003112 \%$ wt. The amount of absorbed hydrogen concentration also increases with increasing pressure. Therefore the highest amount of hydrogen concentration is at a pressure of $15 \mathrm{~atm}$ with a value of $0.041916 \% \mathrm{wt}$. At temperatures of $273 \mathrm{~K}$ and $293 \mathrm{~K}$ the amount of hydrogen concentration at $1 \mathrm{~atm}$ is $0.001556 \% \mathrm{wt}$. and $0.001556 \% \mathrm{wt}$ respectively. While the largest hydrogen concentration value is at $15 \mathrm{~atm}$, which is equal to $0.038817 \%$ wt. and $0,032611 \%$ wt.

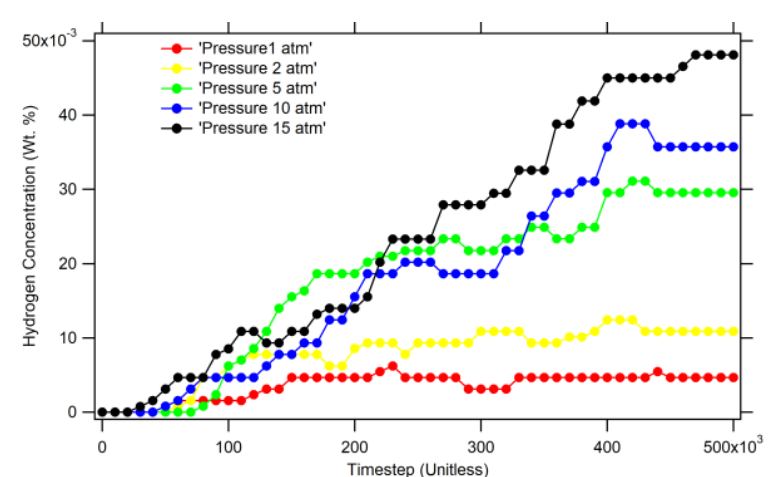

(a)

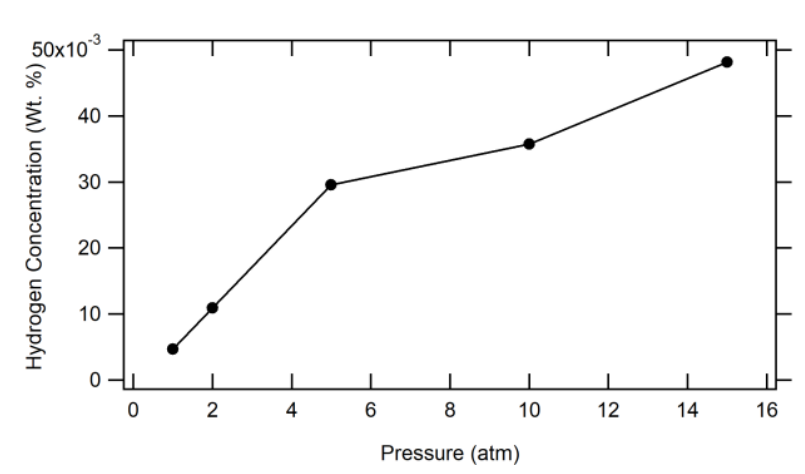

(b)

Figure 5. (a) The hydrogen concentration adsorption at $233 \mathrm{~K}$, (b) The amount of hydrogen concentration at $233 \mathrm{~K}$ to pressure in 480000 timestep. 


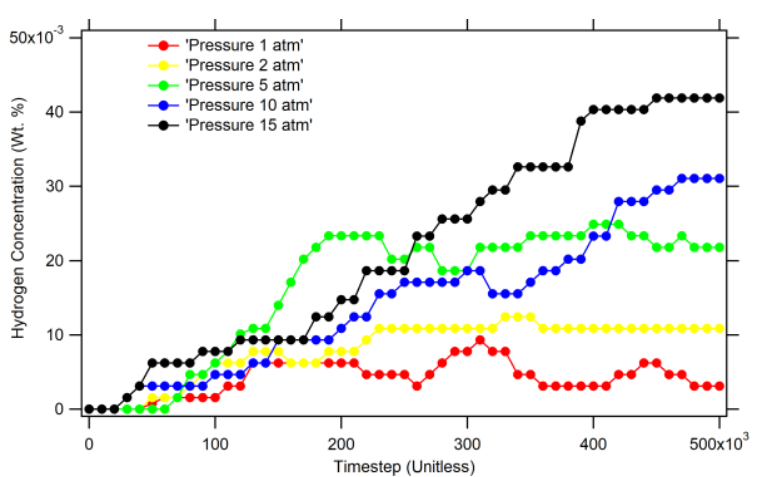

(a)

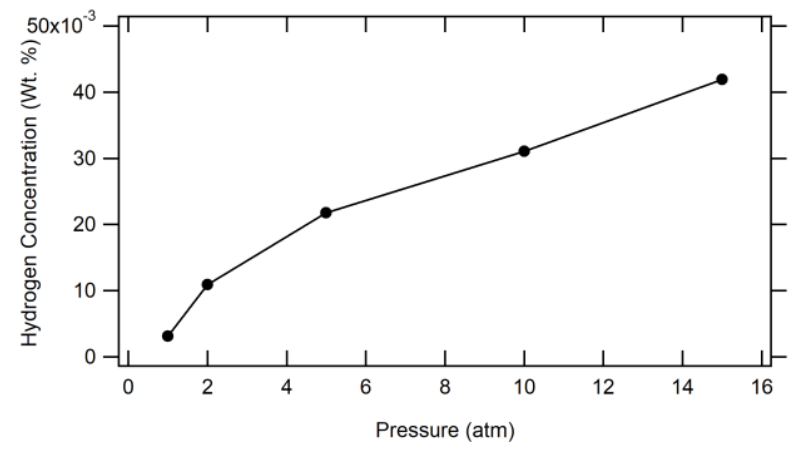

(b)

Figure 6. (a) The hydrogen concentration adsorption at $253 \mathrm{~K}$, (b) The amount of hydrogen concentration at $253 \mathrm{~K}$ to pressure in 480000 timestep.

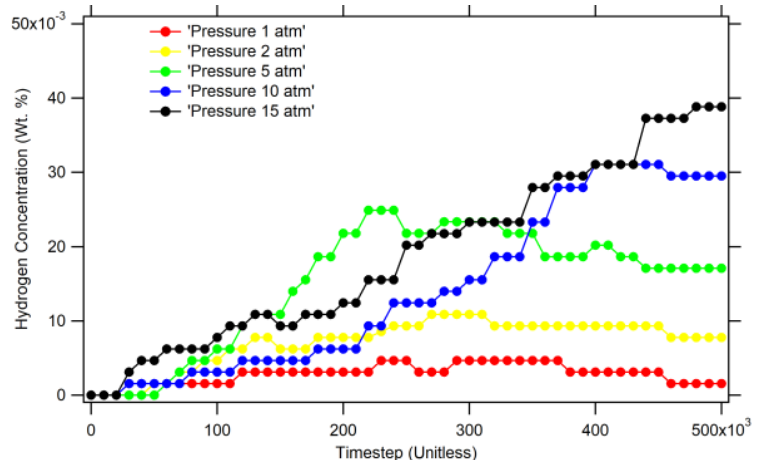

(a)

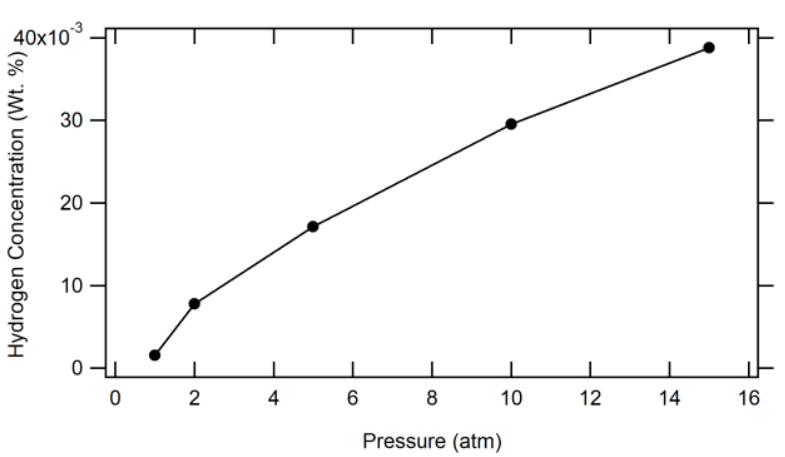

(b)

Figure 7. (a) The hydrogen concentration adsorption at $273 \mathrm{~K}$, (b) The amount of hydrogen concentration at $273 \mathrm{~K}$ to pressure in 480000 timestep.

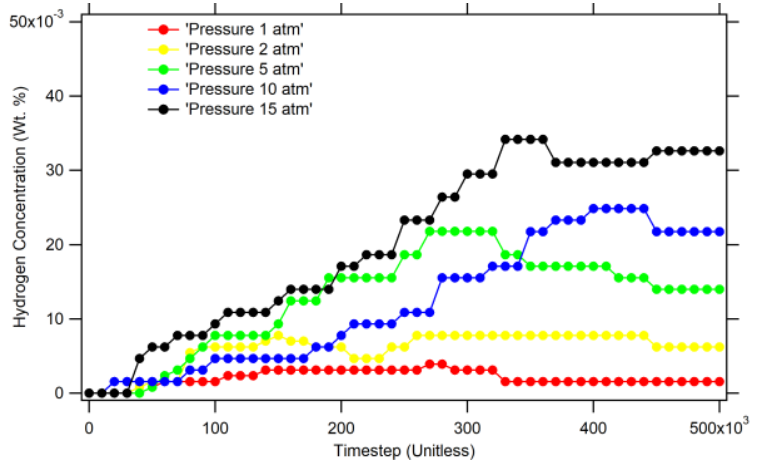

(a)

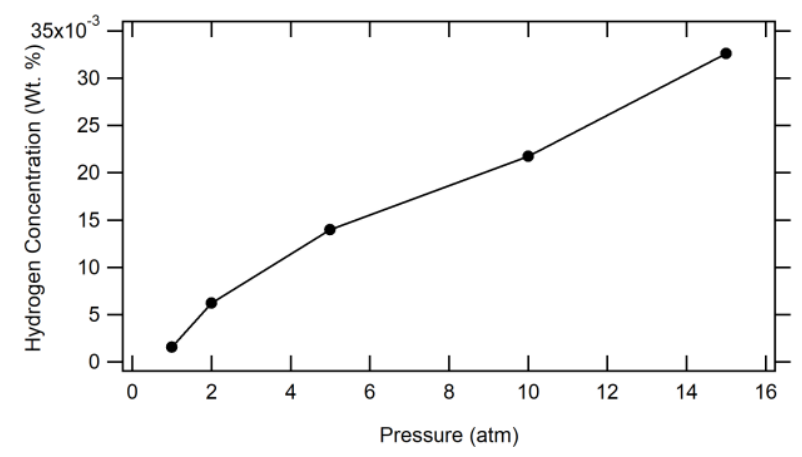

(b)

Figure 8. (a) The hydrogen concentration adsorption at $293 \mathrm{~K}$, (b) The amount of hydrogen concentration at $293 \mathrm{~K}$ to pressure in 480000 timestep. 


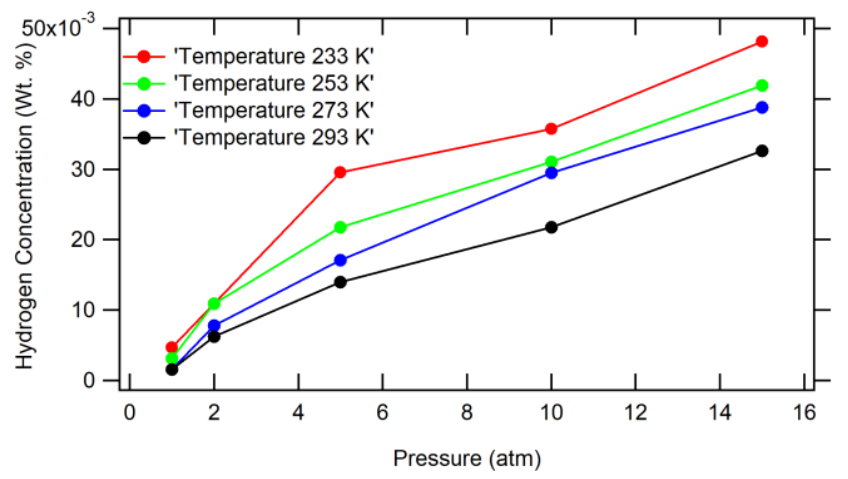

Figure 9. The hydrogen concentration adsorption at different temperature

After the simulation have been conduct at $233 \mathrm{~K}, 253 \mathrm{~K}, 273 \mathrm{~K}$ and $293 \mathrm{~K}$, it can be seen the effect of temperature on the amount of hydrogen absorbed at 1, 2, 5, 10, and $15 \mathrm{~atm}$ pressures. Figure 9 shows the relationship between the concentration of hydrogen to pressure at different temperatures on the same timestep. From Figure 9, it is known that temperature also affects the hydrogen adsorption process. The amount adsorbed is decreases with increasing in temperature. This is in accordance with Le Chatelier's principle and Zhang et al., research, which is an increase in temperature causes a decrease in storage capacity so that the amount that is adsorbed will be less (Z. Zhang, Liu, \& Li, 2017).

There is a possibility to valitdate the data produced by simulation using molecular dynamics method based on $\mathrm{H}_{2}$ Temperature Programmed Reduction (TPR) data, but as far as we acknowledge, no experimental results have been published. The method of experiments should be similar with this (Ammendola, Raganati, \& Chirone, 2017) just with the substitution of gas and material.

\section{Conclusion}

We can conclude that this molecular dynamics simulation has successfully visualized the hydrogen adsorption mechanism in amorphous silica. The hydrogen adsorption by amorphous silica at lower temperatures such as at $233 \mathrm{~K}$ has a higher amount of hydrogen concentration than at higher temperatures $(253 \mathrm{~K}, 273 \mathrm{~K}$, and $293 \mathrm{~K})$. In this simulation the trend of hydrogen adsorbed in amorphous silica is influenced by two main factors, temperature and pressure. As the temperature increases at a constant pressure, the amount of hydrogen that adsorbed will be decreases. While the trend of the amount of hydrogen absorbed will growth with increasing pressure at a constant temperature. The optimum temperature for hydrogen adsorption in amorphous silica in this simulation is $233 \mathrm{~K}$ and 15 atm pressure with the highest adsorption value which is $0.048116 \%$ wt. So we can say that amorphous silica can be one of promising candidates as hydrogen storage media.

\section{References}

Abe, J. O., Popoola, A. P. I., Ajenifuja, E., \& Popoola, O. M. (2019). Hydrogen energy , economy and storage : Review and recommendation. International Journal of Hydrogen Energy, 44(29), 1507215086. https://doi.org/10.1016/j.ijhydene.2019.04.068

Ammendola, P., Raganati, F., \& Chirone, R. (2017). $\mathrm{CO}_{2}$ adsorption on a fine activated carbon in a sound assisted fluidized bed: Thermodynamics and kinetics. Chemical Engineering Journal, 322. https://doi.org/10.1016/j.cej.2017.04.037

Dalebrook, A. F., Gan, W., \& Grasemann, M. (2013). Hydrogen storage: beyond conventional methods. Chemical Communications, 49, 8735-8751. https://doi.org/10.1039/c3cc43836h

Dhaneswara, D., Utami, S., Adriyani, A., Putranto, D. A., \& Delayori, F. (2018). The Effect of Pluronic 123 Surfactant concentration on The $\mathrm{N}_{2}$ Adsorption Capacity of Mesoporous Silica SBA-15: Dubinin-Astakhov Adsorption Isotherm Analysis, (April). https://doi.org/10.1088/17426596/1011/1/012017

Du, X. M., Huang, Y., \& Wu, E. D. (2011). Hydrogen Storage in A-type Zeolite by Grand Canonical Monte Carlo Simulation. Applied Mechanics and Materials, 55-57, 1518-1522. https://doi.org/DOI 
10.4028/www.scientific.net/AMM.55-57.1518

Durbin, D. J., \& Malardier-Jugroot, C. (2013). Review of hydrogen storage techniques for on board vehicle applications. International Journal of Hydrogen Energy, 38, 14595-14617. https://doi.org/10.1016/j.ijhydene.2013.07.058

Dürr, M., \& Höfer, U. (2006). Dissociative adsorption of molecular hydrogen on silicon surfaces. Surface Science Reports, 61(12), 465-526. https://doi.org/10.1016/j.surfrep.2006.08.002

Dutta, S. (2014). A review on production, storage of hydrogen and its utilization as an energy resource. Journal of Industrial and Engineering Chemistry, 20(4), 1148-1156. https://doi.org/10.1016/j.jiec.2013.07.037

Fatriansyah, J. F., Dhaneswara, D., Abdurrahman, M. H., Kuskendrianto, F. R., \& Yusuf, M. B. (2019). Molecular Dynamics Simulation of Hydrogen Adsorption on Silica. IOP Conf. Series: Materials Science and Engineering, 478. https://doi.org/10.1088/1757-899X/478/1/012034

Gundiah, G., Govindaraj, A., Rajalakshmi, N., Dhathathreyan, K. S., \& Rao, C. N. R. (2003). Hydrogen storage in carbon nanotubes and related materials. Journal of Materials Chemistry, (February). https://doi.org/10.1039/b207107j

Hudson, M. S. L., Dubey, P. K., Pukazhselvan, D., Pandey, S. K., Kumar, R., Raghubanshi, H., ... Srivastava, O. N. (2009). Hydrogen energy in changing environmental scenario: Indian context. International Journal of Hydrogen Energy, 34(17), 7358-7367. https://doi.org/10.1016/j.ijhydene.2009.05.107

Li, Y., \& Yang, R. T. (2006). Hydrogen Storage in Low Silica Type X Zeolites. The Journal of Physical Chemistry B, 17175-17181. https://doi.org/10.1021/jp0634508

Marbán, G., \& Valdés-solís, T. (2007). Towards the hydrogen economy? International Journal of Hydrogen Energy, 32, 1625-1637. https://doi.org/10.1016/j.ijhydene.2006.12.017

Mashayak, S. Y., \& Aluru, N. R. (2012). Coarse-Grained Potential Model for Structural Prediction of Confined Water. Journal of Chemical Theory and Computation, 8, 1828-1840. https://doi.org/dx.doi.org/10.1021/ct200842c |

Wu, C. Da, Fang, T. H., \& Lo, J. Y. (2012). Effects of pressure, temperature, and geometric structure of pillared graphene on hydrogen storage capacity. International Journal of Hydrogen Energy, 37(19), 14211-14216. https://doi.org/10.1016/j.ijhydene.2012.07.040

Zhang, F., Zhao, P., Niu, M., \& Maddy, J. (2016). The survey of key technologies in hydrogen energy storage. International Journal of Hydrogen Energy, 41(33), 14535-14552. https://doi.org/10.1016/j.ijhydene.2016.05.293

Zhang, Z., Liu, X., \& Li, H. (2017). The grand canonical Monte Carlo simulation of hydrogen adsorption in single-walled carbon nanotubes. International Journal of Hydrogen Energy, 42(7), 4252-4258. https://doi.org/10.1016/j.ijhydene.2016.10.077

Zhou, L. (2005). Progress and problems in hydrogen storage methods. Renewable and Sustainable Energy Reviews, 9, 395-408. https://doi.org/10.1016/j.rser.2004.05.005

Zubizarreta, L., Arenillas, A., \& Pis, J. J. (2009). Carbon materials for $\mathrm{H}_{2}$ storage. International Journal of Hydrogen Energy, 34(10), 4575-4581. https://doi.org/10.1016/j.ijhydene.2008.07.112

Züttel, A. (2003). Materials for hydrogen storage. Materials Today, 6(9), 24-33. https://doi.org/10.1016/S1369-7021(03)00922-2 